\title{
Letter to the Editor: Bariatric Surgery Worldwide 2013 Reveals a Rise in Mini Gastric Bypass
}

\author{
Mervyn Deitel ${ }^{1}$
}

Published online: 29 July 2015

(C) Springer Science+Business Media New York 2015

I enjoyed the paper Bariatric Surgery Worldwide 2013 by Angrisani et al. [1], which is an update of previous important reports by Scopinaro and by Buchwald. A new finding is the rise in mini gastric bypass to 8718 in 2013. Although not included in Fig. 2, this is more than the stated $6326 \mathrm{BPD} / \mathrm{DS}$ (shown as 7169 in Fig. 2).

At the Paris MGB Consensus Conference in 2013, 16,651 mini gastric bypasses (MGBs) had been performed by the attendees [2]. Also, although the USA/ Canada tally states "not available" since the ASMBS does not currently recognize this operation, there were more than 100 MGBs performed in 2013 in each of Davenport, FL, Joplin, MO, and Las Vegas, NV. In Canada, members of the Sikh community had undergone $>100$ MGBs in 2013 out of country (with >50 from Brampton, ON). Furthermore, in Taiwan and southern Spain, some MGBs in 2013 were reported as "gastric bypass" and assigned as RYGB. Large MGB series have been reported [3-5].

Indicating the trends in bariatric operations is a difficult but valuable task for the authors. I write this letter to point out the increase in MGB worldwide, which is not mentioned anywhere in this report [1].

Mervyn Deitel

book@obesitysurgery.com

1 Obesity Surgery, 39 Bassano Road, Toronto, ON M2N 2J9, Canada
Conflict of Interest The author declares that he has no competing interests. The COI form was sent to Deana Rodriguez.

Ethical Approval The letter is not a study with human participants. There are no experiments on animals.

This letter does not contain any studies on human participants or animals performed by the author.

There is no identifying information of participants.

\section{References}

1. Angrisani L, Santonicola A, Iovino P, et al. Bariatric surgery worldwide 2013. Obes Surg. 2015.

2. Deitel M. Mini-gastric (one-anastomosis) bypass becoming a mainstream operation. Bariatric News. 2013;18:13.

3. Musella M, Sousa A, Greco F, et al. The laparoscopic mini-gastric bypass: the Italian experience: outcomes from 974 consecutive cases in a multi-center review. Surg Endosc. 2014;28:156-63.

4. Kular KS, Manchanda N, Rutledge R. A 6-year experience with 1, 054 mini-gastric bypasses - first study from Indian subcontinent. Obes Surg. 2014;24:1430-5.

5. Chevallier JM, Arman GA, Guenzi M, et al. One thousand single anastomosis (omega loop) gastric bypasses to treat morbid obesity in a 7-year period: outcomes show few complications and good efficacy. Obes Surg. 2015;25:951-8. 